\title{
Experimental evolution reveals nitrate tolerance mechanisms in Desulfovibrio vulgaris
}

\author{
Bo Wu $\mathbb{1}^{1,2}$ - Feifei Liu $\mathbb{1}^{2,3}$ - Aifen Zhou ${ }^{2}$ Juan $\mathrm{Li}^{4} \cdot$ Longfei Shu $\mathbb{1}^{1} \cdot$ Megan L. Kempher $\mathbb{1}^{2} \cdot$ Xueqin Yang ${ }^{1}$ • \\ Daliang Ning $\mathbb{D}^{2} \cdot$ Feiyan $\operatorname{Pan}^{2} \cdot$ Grant M. Zane $\mathbb{D}^{5} \cdot$ Judy D. Wall $\mathbb{D}^{5} \cdot$ Joy D. Van Nostrand $\mathbb{D}^{2} \cdot$ Philippe Juneau $\mathbb{(}^{6} \cdot$ \\ Shouwen Chen $\mathbb{1}^{7,8} \cdot$ Qingyun Yan $\mathbb{1}^{1,2} \cdot$ Jizhong Zhou $\mathbb{1}^{2,9,10} \cdot$ Zhili $\mathrm{He} \mathbb{1}^{1,2,4}$
}

Received: 12 March 2020 / Revised: 9 August 2020 / Accepted: 17 August 2020 / Published online: 15 September 2020

(c) The Author(s), under exclusive licence to International Society for Microbial Ecology 2020

\begin{abstract}
Elevated nitrate in the environment inhibits sulfate reduction by important microorganisms of sulfate-reducing bacteria (SRB). Several SRB may respire nitrate to survive under elevated nitrate, but how SRB that lack nitrate reductase survive to elevated nitrate remains elusive. To understand nitrate adaptation mechanisms, we evolved 12 populations of a model SRB (i.e., Desulfovibrio vulgaris Hildenborough, DvH) under elevated $\mathrm{NaNO}_{3}$ for 1000 generations, analyzed growth and acquired mutations, and linked their genotypes with phenotypes. Nitrate-evolved (EN) populations significantly $(p<0.05)$ increased nitrate tolerance, and whole-genome resequencing identified 119 new mutations in 44 genes of 12 EN populations, among which six functional gene groups were discovered with high mutation frequencies at the population level. We observed a high frequency of nonsense or frameshift mutations in nitrosative stress response genes (NSR: DVU2543, DVU2547, and DVU2548), nitrogen regulatory protein C family genes (NRC: DVU2394-2396, DVU2402, and DVU2405), and nitrate cluster (DVU0246-0249 and DVU0251). Mutagenesis analysis confirmed that loss-of-functions of NRC and NSR increased nitrate tolerance. Also, functional gene groups involved in fatty acid synthesis, iron regulation, and twocomponent system $(L y t R / L y t S)$ known to be responsive to multiple stresses, had a high frequency of missense mutations. Mutations in those gene groups could increase nitrate tolerance through regulating energy metabolism, barring entry of nitrate into cells, altering cell membrane characteristics, or conferring growth advantages at the stationary phase. This study advances our understanding of nitrate tolerance mechanisms and has important implications for linking genotypes with phenotypes in DvH.
\end{abstract}

\section{Introduction}

Sulfate-reducing bacteria (SRB) carry out dissimilatory sulfate reduction, and play an important role in the

Supplementary information The online version of this article (https:// doi.org/10.1038/s41396-020-00753-5) contains supplementary material, which is available to authorized users.

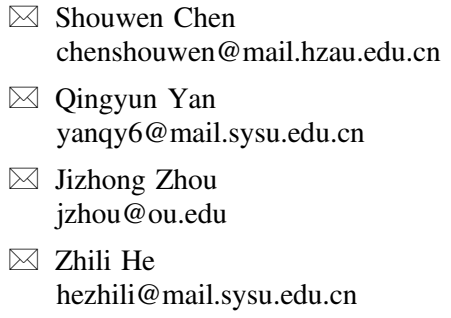

Extended author information available on the last page of the article biogeochemical cycling of sulfur, carbon, nitrogen, and metals [1, 2]. They are ubiquitous in anaerobic environments such as marine and lacustrine sediments [3], where nitrate and sulfate are commonly found [4-6]. Nitrate concentrations in natural environments are generally $<2$ $\mathrm{mM}[7,8]$, while in contaminated sites, nitrate concentrations can be greater than $100 \mathrm{mM}$ [9]. Elevated nitrate could inhibit sulfate reduction performed by SRB due to its competition for organic electron donors [6], which has a special importance in contaminated or engineered systems since it mitigates sulfide production in the environment [10-12]. To confer an advantage under elevated nitrate, several SRB can use nitrate as an alternative electron acceptor [13]. However, the model SRB, Desulfovibrio vulgaris Hildenborough $(\mathrm{DvH})$ lacks a functional nitrate reductase $[14,15]$, and how it responds to elevated nitrate and thrives in such environments for a long time exposure remains elusive [16]. Therefore, it is important to 
understand nitrate tolerance mechanisms, and we used DvH to advance our knowledge about SRB responses and functions in the environment in this study.

Previous studies showed complex responses of DvH to elevated nitrate by different approaches, such as iTRAQ peptide tags [17], microarrays [4], transposon liquid enrichment sequencing (TnLE-seq) [18], and mutagenesis [19]. For example, transcriptomic analysis of DvH showed that elevated nitrate up-regulated key functional genes involved in osmotic, ionic, and nitrite stress responses, and few common patterns of gene expression were observed in response to elevated nitrate, nitrite, or salt [4]. Further analyses indicated that a specific nitrate cluster (DVU0245DVU0251) was related to increased nitrate tolerance, but not for nitrite tolerance in $\mathrm{DvH}$ [18], and elevated nitrate and nitrite had distinct effects on inhibition of $\mathrm{DvH}$ by mutagenesis [19]. Although these studies have provided new insights into our understanding of the response of $\mathrm{DvH}$ to short-term exposure to elevated nitrate at the protein, transcriptional and gene levels, more studies are needed to reveal the genetic basis of nitrate tolerance when $\mathrm{DvH}$ is exposed to elevated nitrate that mimics an environmental stress, especially for a long time.

Experimental evolution of asexual microbial populations coupled with whole-genome resequencing provides a powerful approach to identify adaptive mutations and elucidate genotype-phenotype relationships [20, 21]. Beneficial mutations typically emerge after an adaptive evolution of microorganisms [20, 22], which has been used to discover adaptive changes under specific conditions for prokaryotes such as Escherichia coli, Pseudomonas aeruginosa, and Desulfovibrio vulgaris [22-26], phages $\phi 6$ and T4 [27, 28], and eukaryotes such as Saccharomyces cerevisiae and Chlamydomonas reinhardtii [29, 30]. For example, a previous study indicated a rapid selective sweep of mutations occurred in D. vulgaris populations under $\mathrm{NaCl}$ stress within the first 100 generations, and four mutations contributed to shortened lag phases, increased growth rates and biomass yield [23]. Also, identical or similar genetic changes (e.g., mutations occurred in same/similar genes with similar phenotypic changes) in replicate populations are considered as a strong indicator of beneficial mutations resulting from stress adaptation in the experimental evolution [31-34]. Parallel evolutionary losses of ribose catabolic function occurred in $12 \mathrm{E}$. coli populations during 2000 generations in a glucose minimal medium to gain beneficial fitness in glucose-limited environments [35], and such genetic parallelism at the population level was also observed in the gene Dde_2265 encoding sulfate adenylythransferase (sat) in Desulfovibrio alaskensis evolved under perchlorate stress for about 117 generations, leading to increased perchlorate tolerance [36]. Therefore, it is expected that experimental evolution and resequencing of whole genomes provide powerful approaches to link genotypes to phenotypes, and explore nitrate tolerance mechanisms in DvH.

In this study, we aimed to understand nitrate tolerance mechanisms in DvH through experimental evolution, which could provide a comprehensive understanding of genetic basis of the adaptation evolution in DvH. We hypothesized that a set of beneficial genetic changes would emerge in DvH populations after exposure to elevated nitrate $\left(\mathrm{NaNO}_{3}\right)$ for 1000 generations [22, 23], and that some of these mutations would be parallel among evolved populations [20, 32, 34, 36]. We evolved 12 populations of DvH under elevated nitrate for 1000 generations, compared genotypic and phenotypic characteristics of ancestral (AN) populations and EN populations, linked their genotypes with phenotypes by mutagenesis, and explored its nitrate tolerance mechanisms. We found that six functional groups with a high frequency of mutations, which were directly or indirectly involved in nitrate tolerance. Most importantly, we showed new evidence that nonsense and frameshift mutations in key nitrate associated genes conferred nitrate tolerance and genetic parallelism in nitrate-evolved populations. This study advances our understanding of nitrate tolerance mechanisms in DvH.

\section{Materials and methods}

\section{Strains, cultivation conditions, and propagation}

We used 12 AN populations (AN1-12) of D. vulgaris Hildenborough (ATCC 29579) from a previous study [37], and a clone of DvH was the founder of 12 populations. The first subculture was non-stressed for all 12 populations, and they were frozen to serve as 12 AN populations, from which we randomly chose three $\mathrm{AN}$ populations (AN2, AN8, and AN11) to determine a suitable $\mathrm{NaNO}_{3}$ concentration for experimental evolution, which allowed AN populations to reach a stationary phase within $48 \mathrm{~h}$ (Fig. S1). AN populations were grown at $37^{\circ} \mathrm{C}$ and propagated in the defined LS4D medium [38] amended with $10 \mathrm{mM} \mathrm{NaNO}$ for 500 generations, then with $30 \mathrm{mM} \mathrm{NaNO}$ for another 500 generations to keep ongoing nitrate selective pressure for DvH populations. Cultures were propagated by transferring $1 \%(100 \mu \mathrm{L})$ of the final volume $(10 \mathrm{~mL})$ into a fresh medium every $48 \mathrm{~h}$, and populations were archived every 100 generations at $-80{ }^{\circ} \mathrm{C}$ for later studies. Every $48 \mathrm{~h}$, the $\mathrm{OD}_{600}$ was recorded for each population before transfer (Fig. S2), and the statistical significance of biomass differences $\left(\mathrm{OD}_{600}\right)$ of 6.7 generations (after the first transfer) vs. 1000 generations (after the last transfer) was based on ANOVA tests. 


\section{Growth phenotypes of ancestral and evolved populations}

The growth of both $\mathrm{AN}$ and nitrate-evolved (EN) populations in the LS4D medium with $30 \mathrm{mM}$ or $100 \mathrm{mM} \mathrm{NaNO}$ or without additional $\mathrm{NaNO}_{3}$ was measured by a spectrophotometer (Thermo Spectronic 20D+, Waltham, Massachusetts, USA) with three replicates for each population, and $\mathrm{OD}_{600}$ values of all populations were recorded every $2-3 \mathrm{~h}$ over a period of $70 \mathrm{~h}$. Lag phase was defined as the time afterinoculation to $\mathrm{OD}_{600}=0.2$; growth rate was $2.303 \times$ the slope of the linear portion of growth curve by plotting $\mathrm{Ln}\left(\mathrm{OD}_{600}\right)$ as the $y$-axis and time as the $x$-axis; biomass yield was the maximum $\mathrm{OD}_{600}$ as previously described [37]. Statistical significance of multiple pairwise-comparison was based on the ANOVA test. In addition, extracellular nitrate concentration of AN and EN populations was measured by ion chromatography (ICS-90A, Dionex, USA).

\section{Genomic DNA extraction and whole-genome resequencing of $A N$ and EN populations}

Genomic DNA (gDNA) of all AN and EN populations was extracted with a GenElute Bacterial Genomic DNA kit (Sigma) following the manufacturer's instructions. The quality of gDNA was assessed with a Nanodrop ND-1000 (Thermo Fisher Scientific, Inc., Wilmington, DE, USA). Illumina HiSeq sequencing of gDNA samples was conducted at the Oklahoma Medical Research Foundation (Oklahoma City, OK, USA) following standard library preparation protocols and Illumine sequencing protocols. The sequencing data have been deposited into NCBI Sequence Read Archives and are accessible through Bioproject PRJNA630554.

\section{Mutation calling}

Mutations in all AN and EN populations were called by our in-house pipeline (http://zhoulab5.rccc.ou.edu:8080/) with the DvH genome sequence (NC_002937.3) as the reference. Btrim was used for quality control with filter parameter settings, including windows size as 5 , average quality score as 30 and minimal insert size as 50 [39]. The alignment was generated by Bowtie2, and the default settings of bowtiw2build and bowtie2-x were used for database building and alignments [40]. Samtools was used to call mutations including single nucleotide polymorphisms (SNPs) and insertions/deletions (INDELs); Samtools-mplieup was used to filter variants, probabilistic realignment for computation of base alignment quality was disabled to reduce false SNPs caused by misalignments, minimum mapping quality for alignment was 0 , and minimum base quality for a base was 13 [41]. The output variant call format (VCF) file was generated by Bcftools [42]. Phred scale quality score was used as the filter score. Breseq was also used to call mutations with the default setting [43], and new junctions/insertions in output/ index.html and output/marginal.html (allele frequency $>10 \%$ ) were added into the mutation data analysis. Compared to the original NCBI reference DvH strain, the ancestral DvH strain used in this study already has 22 genomic differences [23], which were removed from our mutation analysis. The allele frequency of mutations was calculated based on DP4 values: forward reference alleles, reverse reference alleles, forward alter alleles, and reverse alter alleles by Samtools [41].

\section{Mutation validation}

To validate mutations called in this study, a subset of regions bearing mutations with different filter values were chosen (Table S1). Genomic DNA from AN or EN populations was extracted and amplified by PCR, and PCR amplicons were sequenced by a Sanger platform at the Oklahoma Medical Research Foundation to verify those mutations identified by the Illumina sequencing platform. All the primers used in this study are listed in Table S1.

\section{Mutation data analysis and prediction of mutated protein structure}

Mutations were assigned to a gene if they occurred within a coding region or within a 100-bp upstream of open reading frames [44]. We combined output VCF files of whole-genome sequence data from Bcftools [42] to generate SNPs/INDELs tables for AN or EN populations (Tables S2 and S3). Briefly, mutation data analysis included five major steps: (i) all mutation information was extracted from output VCF files of AN and EN populations, including gene name, position for the mutation, mutated bases and reference bases; (ii) proteins encoded by these genes and Clusters of Orthologous Groups (COGs) of the proteins [45] were added into the table manually; (iii) as mutations or polymorphisms were detected in the ancestor [23], we only analyzed newly acquired mutations in the EN population (defined as newly acquired mutations), including new junctions occurred in coding genes that predicted by breseq (Table S4); (iv) to focus on mutated functional genes with newly acquired mutations in EN populations, a gene identified with newly acquired mutations was labeled with the highest allele frequency of the mutation occurring in the gene for each EN population (Table S5); and (v) gene co-expression prediction was based on information in operon and regulon prediction in Microbesonline (http://www.microbesonline. org/), and experimental evidence was based on publications about mutated genes, especially genes that were comentioned in same publication identified by String [46]. 
Table 1 Strains and plasmids used in this study.

\begin{tabular}{|c|c|c|}
\hline Strain/plasmid & Genotype or relevant characteristics & $\begin{array}{l}\text { Source or } \\
\text { reference }\end{array}$ \\
\hline $\begin{array}{l}\text { Escherichia coli } \alpha \text {-select } \\
\text { (silver efficiency) }\end{array}$ & $\begin{array}{l}\Phi 80 \mathrm{~d} / \text { lacZ } \Delta \mathrm{M} 15, \Delta(\text { lacZYA-argF }) \mathrm{U} 169, \text { recA1, endA1, } \\
h s d R 17\left(r_{\mathrm{K}}^{-}, m_{\mathrm{K}}^{+}\right), \text {phoA, supE44, } \lambda^{-}, \text {thi- } 1, \text { gyrA96, relA } 1\end{array}$ & Bioline \\
\hline \multicolumn{3}{|l|}{ Desulfovibrio vulgaris } \\
\hline JZ001 & $\begin{array}{l}\text { Wild type (pDV1) } \Delta u p p ; 5-\mathrm{FU}^{\mathrm{r}} \text { (Parent strain for marker } \\
\text { exchange mutants) }\end{array}$ & This study \\
\hline ME2394 & JZ001 $\Delta$ DVU2394:: (npt upp); $\mathrm{Km}^{\mathrm{r}}, 5-\mathrm{FU}^{\mathrm{s}}$ & This study \\
\hline ME2395 & JZ001 $\Delta$ DVU2395:: (npt upp); $\mathrm{Km}^{\mathrm{r}}$, 5-FU ${ }^{\mathrm{s}}$ & This study \\
\hline ME2396 & JZ001 $\Delta$ DVU2396:: (npt upp); $\mathrm{Km}^{\mathrm{r}}, 5-\mathrm{FU}^{\mathrm{s}}$ & This study \\
\hline ME2405 & JZ001 $\Delta$ DVU2405:: (npt upp); $\mathrm{Km}^{\mathrm{r}}, 5-\mathrm{FU}^{\mathrm{s}}$ & This study \\
\hline ME2543 & JZ001 $\Delta$ DVU2543:: (npt upp); $\mathrm{Km}^{\mathrm{r}}, 5-\mathrm{FU}^{\mathrm{s}}$ & This study \\
\hline ME2547 & $\mathrm{JZ001} \Delta \mathrm{DVU} 2547::\left(\right.$ npt upp); $\mathrm{Km}^{\mathrm{r}}, 5-\mathrm{FU}^{\mathrm{s}}$ & This study \\
\hline ME2548 & JZ001 $\Delta$ DVU2548:: (npt upp); $\mathrm{Km}^{\mathrm{r}}, 5-\mathrm{FU}^{\mathrm{s}}$ & This study \\
\hline pMO719 & pCR8/GW/TOPO containing SRB replicon (pBG1); $\mathrm{Sp}^{\mathrm{r}}$ & [49] \\
\hline pMO746 & 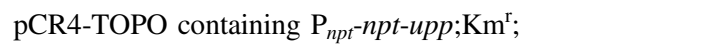 & [49] \\
\hline pMO719-DVU2394 & $\begin{array}{l}\text { pMO719 containing DNA fragment 2500764-2500995:: } \\
\text { DVU2394: } \mathrm{Sp}^{\mathrm{r}}\end{array}$ & This study \\
\hline pMO719-DVU2395 & $\begin{array}{l}\text { pMO719 containing DNA fragment 2500764-2500995:: } \\
\text { DVU2395: } \mathrm{Sp}^{\mathrm{r}}\end{array}$ & This study \\
\hline pMO719-DVU2396 & $\begin{array}{l}\text { pMO719 containing DNA fragment 2500764-2500995:: } \\
\text { DVU2396: } \mathrm{Sp}^{\mathrm{r}}\end{array}$ & This study \\
\hline pMO719-DVU2405 & $\begin{array}{l}\text { pMO719 containing DNA fragment 2511308-2511461:: } \\
\text { DVU2405: } \mathrm{Sp}^{\mathrm{r}}\end{array}$ & This study \\
\hline pMO719-DVU2543 & $\begin{array}{l}\text { pMO719 containing DNA fragment 2653710-2653863:: } \\
\text { DVU2543; } \mathrm{Sp}^{\mathrm{r}}\end{array}$ & This study \\
\hline pMO719-DVU2547 & $\begin{array}{l}\text { pMO719 containing DNA fragment 2661298-2661384:: } \\
\text { DVU2547; } \mathrm{Sp}^{\mathrm{r}}\end{array}$ & This study \\
\hline
\end{tabular}

Types of detected mutations in this study include: (i) nonsense mutation: one-base change in a DNA sequence that results in a premature stop codon; (ii) frameshift mutation: an insertion or deletion in a DNA sequence that often results in a non-functional protein (e.g., truncated proteins) [47]; (iii) missense mutation: one-base change in a DNA sequence that results in a different amino acid in the mature protein; and (iv) silent mutation: one-base substitution in a DNA sequence that does not involve amino acid replacement in the coded protein.

We also used Phyre2 [48] to predict changes in the tertiary structure of HcpR encoded by DVU2547, one of the most frequently mutated genes in EN populations with the highest hits (>99\% confidence) for predicted models (Fig. S3).

\section{Mutagenesis and growth phenotypes of deletion mutants}

DvH strain JZ001 ( $\Delta u p p)$ was generated using the founder strain of AN populations, and this strain was used as the parental strain to generate marker exchange (ME) mutants of genes by a marker replacement approach [49]. The growth of parental strain and ME mutants of NSR was tested in LS4D, LS4D + $30 \mathrm{mM} \mathrm{NaNO} 3$ and LS4D $+0.15 \mathrm{mM} \mathrm{NaNO}$. The growth phenotypes of the parental strain and ME mutants of NRC genes were tested in LS4D, LS4D + $30 \mathrm{mM} \mathrm{NaNO}$, and LS4D + $100 \mathrm{mM} \mathrm{NaCl}$. Genetic complementation was done for all the mutants (ME2394, ME2395, ME2396, ME2405, ME2543, ME2547, and ME2548) and EN7 variant complemented with the plasmid containing a native promoter, ribosome binding site and wild type gene (Table 1). Further reverse-transcription PCR was done for the mutants and their complemented strains at the exponential phase to confirm the expression of complemented genes. The growth of complemented strains was tested in LS4D and LS4D + $30 \mathrm{mM} \mathrm{NaNO}$. Statistical significance of growth parameters was based on the T-test. All DvH strains used in this study are listed in Table 1. 


\section{Results}

\section{Nitrate tolerance increased in nitrate-evolved populations}

To choose a suitable nitrate concentration for our experimental evolution, three ancestral (AN) populations (AN2, AN8, and AN11) were randomly selected and grown under different nitrate concentrations. Their lag phase increased while growth rates and biomass gradually decreased as nitrate concentrations increased from $0 \mathrm{mM}$ to $30 \mathrm{mM}$ (Fig. $\mathrm{S} 1)$. We evolved 12 populations under elevated nitrate (10 or $30 \mathrm{mM} \mathrm{NaNO}$ ), which is higher than nitrate concentrations in natural environments for 1000 generations, and all 12 nitrate-evolved (EN) populations reached a higher biomass compared to AN populations (Fig. S2).

EN populations had a shorter lag phase (Fig. 1a) and a faster growth rate (Fig. 1b) compared to AN populations under normal growth conditions and showed significantly $(p<0.05)$ higher nitrate tolerance compared to AN populations (with $30 \mathrm{mM} \mathrm{NaNO}$ ) (Fig. 1). With $100 \mathrm{mM}$ additional $\mathrm{NaNO}_{3}$, the growth of EN populations was repressed but they could still grow relatively well while AN populations barely grew within $70 \mathrm{~h}$ (Fig. 1). The nitrate concentration $(30 \mathrm{mM})$ did not change at the end of the cultivation period for $\mathrm{AN}$ or EN populations, indicating that a change in nitrate concentration was not detected after $\mathrm{DvH}$ was evolved for 1000 generations under elevated nitrate.

\section{Genes and functional gene groups with new mutations in EN populations}

Sequencing reads of $\mathrm{AN}$ and EN populations covered about 99\% of the DvH reference genome sequence (NC_002937.3) with an average sequencing depth of $88 \times$ for AN populations, and $92 \times$ for EN populations. A total of 58 and 167 mutations were respectively detected in AN and EN populations, and the number of mutations ranged from 8 to 26 for each AN population (Table S2), while the number of mutations ranged from 13 to 33 for each EN population (Table S3). We focused on newly acquired mutations and associated genes in the EN populations, including 119 newly acquired mutations (containing nine large deletions and one insertion predicted using breseq) in 44 genes associated with energy, amino acid, carbohydrate, nucleotide, lipid, and inorganic ion metabolism, cellular process and signal, and information storage and processing (Table S4).

Among those 44 genes with newly acquired mutations, we focused on genes with high mutation frequency at the population level ( $>33 \%$, refs to genes bearing mutations in more than four of $12 \mathrm{EN}$ populations), and six functional gene groups of 19 genes were found based on gene co-
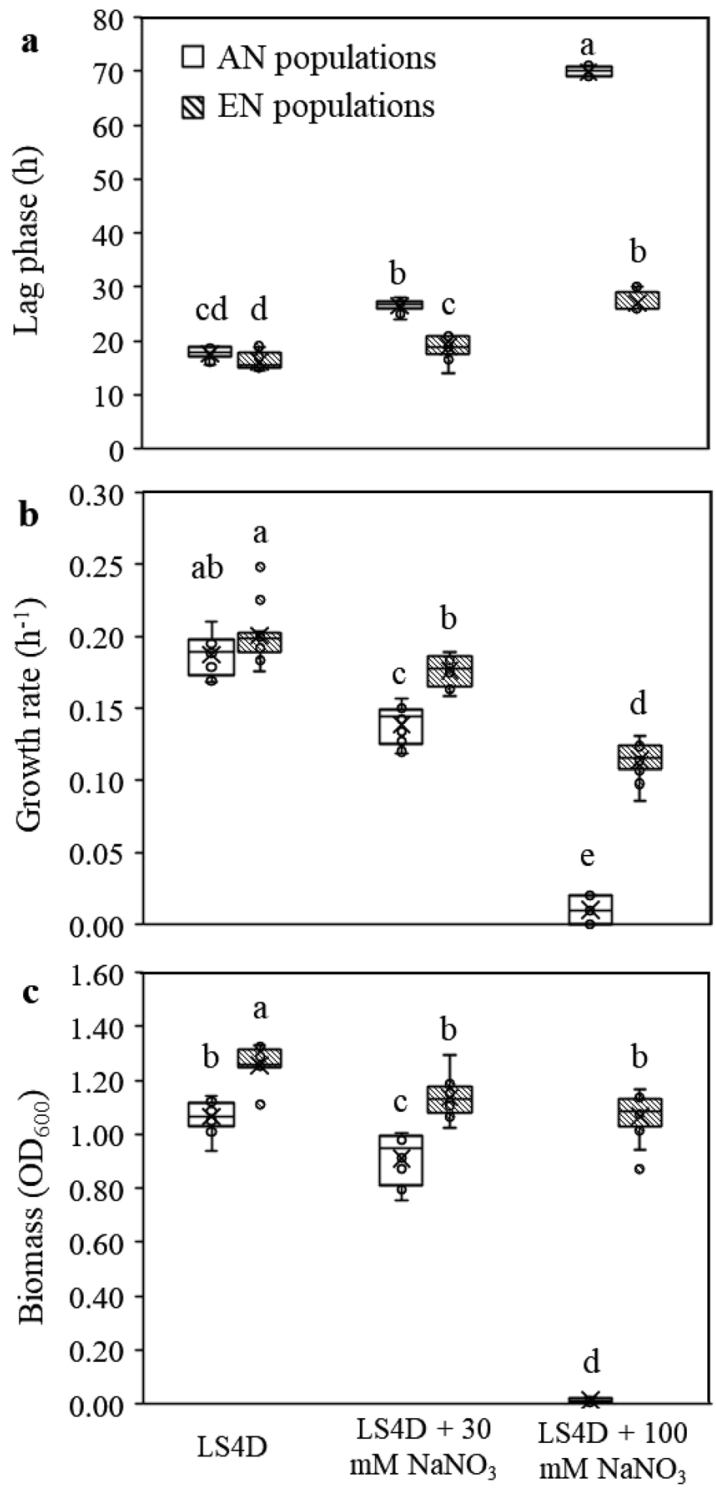

Fig. 1 Increased $\mathrm{NaNO}_{3}$ tolerance in EN populations compared to AN populations. The lag phase (a), growth rate (b), and biomass yield (c) of AN and EN populations in LS4D, LS4D + $30 \mathrm{mM} \mathrm{NaNO}_{3}$, and $\mathrm{LS} 4 \mathrm{D}+100 \mathrm{mM} \mathrm{NaNO}_{3}$ for testing nitrate tolerance. Data are shown as mean \pm standard deviation, and statistical significance was based on the pairwise ANOVA $(* p<0.05)$. No growth was detected for AN populations within $70 \mathrm{~h}$ under $100 \mathrm{mM} \mathrm{NaNO}$.

expression prediction or experimental evidence from previous studies (Tables S4 and S5): (a) nitrosative stress response genes (NSR: DVU2543, DVU2547, and DVU2548): DVU2547 (hybrid cluster protein regulator, $h c p R$ ) harboring nine mutations in seven of $12 \mathrm{EN}$ populations, regulates the expression of DVU2543 ( $h c p$, identical mutation in two EN populations) $[14,50]$ and exists in the same operon with DVU2548 (acpD, five mutations in three EN populations) [51]; (b) nitrogen regulatory protein C family genes (NRC: DVU2394-2396, DVU2402, and DVU2405): a two component system DVU2394 
Table 2 The number of newly acquired mutations in 19 genes of six gene groups in the EN populations.

\begin{tabular}{|c|c|c|c|c|c|}
\hline \multirow[t]{2}{*}{ Gene groups } & \multirow[t]{2}{*}{ Gene } & \multirow[t]{2}{*}{ COGs } & \multirow[t]{2}{*}{ Products } & \multicolumn{2}{|c|}{$\begin{array}{l}\text { No. of EN populations } \\
\text { bearing mutations }\end{array}$} \\
\hline & & & & in gene & in gene group \\
\hline \multirow[t]{3}{*}{ Nitrosative stress response (NSR) genes } & DVU2543 & $\mathrm{C}$ & Hydroxylamine reductase $(h c p)$ & 2 & 12 \\
\hline & DVU2547 & $\mathrm{T}$ & Transcriptional regulator $(h c p R)$ & 7 & \\
\hline & DVU2548 & I & Acyl carrier protein phosphodiesterase $(a c p D)$ & 3 & \\
\hline \multirow[t]{5}{*}{$\begin{array}{l}\text { Nitrogen regulatory protein family } \mathrm{C} \\
(\mathrm{NRC}) \text { genes }\end{array}$} & DVU2394 & $\mathrm{T}$ & $\begin{array}{l}\text { Sigma-54 dependent transcriptional regulator/response } \\
\text { regulator (RR) }\end{array}$ & 5 & 12 \\
\hline & DVU2395 & $\mathrm{T}$ & Sensor histidine kinase (HK) & 5 & \\
\hline & DVU2396 & $\mathrm{C}$ & Alcohol dehydrogenase, iron-containing ( $a d h)$ & 3 & \\
\hline & DVU2402 & $\mathrm{C}$ & Heterodisulfide reductase, A subunit ( $h d r$ ) & 1 & \\
\hline & DVU2405 & $\mathrm{C}$ & Alcohol dehydrogenase, iron-containing ( $a d h)$ & 2 & \\
\hline \multirow[t]{5}{*}{ Nitrate cluster } & DVU0246 & $\mathrm{S}$ & $\begin{array}{l}\text { Pyruvate phosphate dikinase PEP/pyruvate binding } \\
\text { subunit ( } p p d k)\end{array}$ & 5 & 12 \\
\hline & DVU0247 & $\mathrm{T}$ & CheY-like superfamily, response regulator (RR) & 1 & \\
\hline & DVU0248 & $\mathrm{T}$ & Signal transduction histidine kinase (HK) & 6 & \\
\hline & DVU0249 & $\mathrm{P}$ & $\begin{array}{l}\text { Probable phosphite transport system-binding protein, } \\
\text { putative (ptxB) }\end{array}$ & 1 & \\
\hline & DVU0251 & $\mathrm{R}$ & Transmembrane protein TauE like & 3 & \\
\hline \multirow[t]{2}{*}{ Fatty acid synthesis genes } & DVU1204 & IQ & 3-oxoacyl-(acyl-carrier-protein) synthase II ( $f a b)$ & 7 & 9 \\
\hline & DVU1208 & I & Putative glycerol-3-phosphate acyltransferase $(p l s X)$ & 2 & \\
\hline \multirow[t]{2}{*}{ Iron regulatory genes } & DVU0942 & $\mathrm{P}$ & FUR family transcriptional regulator (fur) & 6 & 12 \\
\hline & DVU2571 & $\mathrm{P}$ & Ferrous iron transport protein $\mathrm{B}(f e o B)$ & 6 & \\
\hline \multirow[t]{2}{*}{ LytR/LytS two component system } & DVU0596 & KT & DNA-binding response regulator $(l y t R)$ & 1 & 6 \\
\hline & DVU0597 & $\mathrm{T}$ & Histidine kinase $(l y t S)$ & 5 & \\
\hline
\end{tabular}

(ntrC)/DVU2395 (response regulator/histidine kinase) in the operon DVU2394-DVU2396 (with 18 mutations in 11 EN populations) regulates the operon DVU2397-2405 [52], in which DVU2402 mutated in one EN population and DVU2405 harboring three mutations in two EN populations; (c) nitrate cluster (DVU0246-0249 and DVU0251) [18] with 17 mutations in all $12 \mathrm{EN}$ populations; (d) fatty acid synthesis genes (DVU1204 and DVU1208): DVU1204 (3-oxoacyl-(acyl-carrier-protein (ACP) synthase II, fabF) harboring six mutations in seven $\mathrm{EN}$ populations and DVU1208 (phosphate acyltransferase, plsX) harboring an identical mutation in two EN populations are predicted in one operon involved in fatty acid synthesis [23, 51]; (e) iron regulatory genes (DVU0942 and DVU2571): DVU0942 (fur) harboring four mutations in six EN populations is a regulator of ferrous iron transport protein B gene DVU2571 $(f e o B)[53]$, which mutated in the other six EN populations; and (f) a two component system DVU0596/DVU0597 $($ lytR/lytS) harboring five mutations in six EN populations regulates the expression of carbon starvation protein genes DVU0598 (cstA) and DVU0599 (cstB) [52] (Table 2).

A large proportion (84/119) of mutations occurred in those 19 genes of six functional groups in EN populations (Tables 2 and S4). For example, seven EN populations had mutations in DVU2547, including an identical mutation occurred in EN7 and EN8; nine EN populations had mutations in the two component system DVU2394/ DVU2395; all $12 \mathrm{EN}$ populations harbored mutations in nitrate cluster. For the other 27 mutated genes with 35 newly acquired mutations, we found seven genes with 17 new mutations acquired in at least two EN populations (Table S6), and 18 genes acquired new mutations in only one EN population (Table S5). In the following analysis, we focused on those highly mutated six functional groups (with mutation frequency $\geq 50 \%$ at the populations level) to link their genotypes with phenotypes towards understanding nitrate tolerance mechanisms in DvH.

\section{Six functional gene groups were highly mutated in EN populations}

We further analyzed potential effects of mutations on functions of their associated genes/proteins in the six functional groups. First, nonsense and frameshift mutations were identified in the first three functional gene groups, presumably resulting in premature or truncated proteins. (i) Nonsense and frameshift mutations were identified in the NSR group of three genes with allele frequencies ranged 
Table 3 Newly acquired mutations in nitrosative stress response (NSR) genes in the EN populations.

\begin{tabular}{|c|c|c|c|c|c|c|}
\hline Gene & Populations & Mutation type & $\begin{array}{l}\text { Allele } \\
\text { frequency }(\%)\end{array}$ & Position & Nucleotide change & Amino-acid change \\
\hline \multirow[t]{2}{*}{ DVU2543 hcp } & EN4 & SNP & 99 & 2654808 & $\mathrm{G} \rightarrow \mathrm{A}$ & Trp $\rightarrow$ STOP \\
\hline & EN5 & SNP & 79 & 2654808 & $\mathrm{G} \rightarrow \mathrm{A}$ & $\operatorname{Trp} \rightarrow$ STOP \\
\hline \multirow{10}{*}{$\begin{array}{l}\text { DVU2547 } \\
h c p R\end{array}$} & EN1 & SNP & 74 & 2660114 & $\mathrm{G} \rightarrow \mathrm{T}$ & Gly $\rightarrow$ Val \\
\hline & & Deletion & 13 & 2660166 & $-4:$ GGCG & 27 amino acids changed \\
\hline & & SNP & 17 & 2660388 & $\mathrm{C} \rightarrow \mathrm{T}$ & Pro $\rightarrow$ Ser \\
\hline & EN3 & SNP & 66 & 2660235 & $\mathrm{C} \rightarrow \mathrm{T}$ & Leu $\rightarrow$ Phe \\
\hline & & SNP & 36 & 2660404 & $\mathrm{C} \rightarrow \mathrm{A}$ & Phe $\rightarrow$ Leu \\
\hline & EN6 & SNP & 98 & 2660273 & $\mathrm{C} \rightarrow \mathrm{T}$ & Ser $\rightarrow$ Leu \\
\hline & EN7 & SNP & 100 & 2660403 & $\mathrm{C} \rightarrow \mathrm{T}$ & Gln $\rightarrow$ STOP \\
\hline & EN8 & SNP & 99 & 2660403 & $\mathrm{C} \rightarrow \mathrm{T}$ & Gln $\rightarrow$ STOP \\
\hline & EN9 & SNP & 94 & 2660477 & $\mathrm{C} \rightarrow \mathrm{T}$ & Ser $\rightarrow$ Phe \\
\hline & EN10 & Deletion & 72 & 2660450 & -15:GGCGCGAGGCCATCA & Five amino acids loss \\
\hline \multirow{6}{*}{$\begin{array}{l}\text { DVU2548 } \\
\text { acpD }\end{array}$} & EN2 & Deletion & 93 & 2661113 & $\mathrm{GA} \rightarrow \mathrm{A}$ & Frameshift mutation \\
\hline & & SNP & 46 & 2661114 & $\mathrm{~A} \rightarrow \mathrm{C}$ & Ser $\rightarrow$ Pro \\
\hline & EN8 & Deletion & 21 & 2661089 & $-57 \mathrm{bp}$ & Frameshift mutation \\
\hline & EN11 & Insertion & 71 & 2661301 & $+4:$ CACT & $\begin{array}{l}\text { Three bases upstream of the } \\
\text { start codon }\end{array}$ \\
\hline & & & 62 & 2661319 & +12: CTTGATATACAG & $\begin{array}{l}21 \text { bases upstream of the } \\
\text { start codon }\end{array}$ \\
\hline & EN12 & Deletion & 100 & 2661182 & $\mathrm{CGG} \rightarrow \mathrm{CG}$ & Frameshift mutation \\
\hline
\end{tabular}

from 17 to $100 \%$ (an average of $72 \%$ ). Seven of 17 mutations in this group were fixed or nearly fixed $(>90 \%)$, and interestingly, five of them were nonsense and frameshift mutations. Also, the same mutation was identified in this group, such as a nonsense mutation in coordinate 2654808 in DVU2543 (Hybrid cluster protein, $h c p$ ) in EN4 and EN5, and in position 2660403 of DVU2547 (Hcp regulator, $h c p R$ ) in EN7 and EN8 (Table 3). (ii) Among 22 mutations that occurred in the NRC group, 11 nonsense and frameshift mutations were identified in this group with four of them fixed in all EN populations, and the allele frequency of mutations ranged from 11 to $100 \%$ with an average of $58 \%$ (Table 4). (iii) Nonsense and frameshift mutations were also observed in three genes (DVU0246, DVU0247, and DVU0248) of nitrate cluster with a mutation allele frequency ranged from 13 to $77 \%$ (an average of 36\%). All the mutations occurred in DVU0246 (Pyruvate phosphate dikinase, $p p d k$ ) and DVU0247 (Response regulator, cheY like/RR) could result in truncated proteins. Identical frameshift mutation was identified at the coordinate 279997 of DVU0246 in EN1 and EN8, and the same missense mutation occurred at the coordinate 285948 of DVU0251 (Transmembrane protein, tauE like) in EN 7 and EN 12 (Table 5). Interestingly, eight of ten mutations detected using breseq were located in these three functional groups (NSR, NRC, and nitrate cluster), which were nonsense and frameshift mutations (Table S4).
Second, missense mutations occurred in the other three gene groups, potentially resulting in functional changes in their encoding proteins. Mutations in fatty acid synthesis and iron regulatory genes had higher allele frequencies (43-100\% and $88-100 \%$ with an average of $92 \%$ and $99 \%$, respectively) compared to other gene groups (Table S4). For fatty acid synthesis genes, mutations in DVU1204 ( $f a b F)$ were observed in seven out of $12 \mathrm{EN}$ populations, which were fixed or nearly fixed, and the same SNP was detected in DVU1204 in EN4 and EN5, while a same silent mutation was found in DVU1208 $(p l s X)$ in EN8 and EN10 (Table S7). Also, all EN populations harbored mutations in iron regulatory genes, and the same mutation occurred in DVU0942 (fur) in EN4, EN5, and EN9 (Table S8). In addition, six mutations were detected in $l y t R / l y t S$ with the lowest allele frequency (11-40\% with an average of 19\%) among those six gene groups, but all of the mutations were missense except an intergenic mutation at the upstream of DVU0597 start codon in EN3 (Table S9).

The results showed that nonsense, frameshift and missense mutations occurred in those six gene groups, and they may result in prematurely terminated proteins, truncated proteins, or function-changed proteins, thus affecting functions of $\mathrm{DvH}$ in response to elevated nitrate. Furthermore, as those mutations appeared to parallelly occur in EN populations, it is expected that such observed mutations may be related to increased nitrate tolerance in $\mathrm{DvH}$. 
Table 4 Newly acquired mutations in nitrogen regulatory protein $\mathrm{C}$ family (NRC) genes in the EN populations.

\begin{tabular}{|c|c|c|c|c|c|c|}
\hline Gene & Populations & Mutation type & $\begin{array}{l}\text { Allele } \\
\text { frequency }(\%)\end{array}$ & $\begin{array}{l}\text { Mutation } \\
\text { position }\end{array}$ & Nucleotide change & Amino-acid change \\
\hline \multirow[t]{7}{*}{ DVU2394 } & \multirow[t]{2}{*}{ EN3 } & Deletion & 16 & 2497229 & $-1: \mathrm{G}$ & $\begin{array}{l}2 \text { amino acids } \\
\text { changed }\end{array}$ \\
\hline & & SNP & 59 & 2497736 & $\mathrm{C} \rightarrow \mathrm{T}$ & Glu $\rightarrow$ Lys \\
\hline & EN5 & SNP & 16 & 2496979 & $\mathrm{~T} \rightarrow \mathrm{C}$ & Tyr $\rightarrow$ Cys \\
\hline & EN6 & Deletion & 49 & 2497411 & $-1: G$ & Frameshift mutation \\
\hline & EN7 & Deletion & 100 & 2497258 & -18: GCAATTCACGCACGTTGC & 6 amino acids loss \\
\hline & \multirow[t]{2}{*}{ EN9 } & Deletion & 36 & 2497708 & -19:GAACAGTTCGCTACGGGCC & Frameshift mutation \\
\hline & & Insertion & 11 & 2497728 & +12: GACCGCGGACAT & $\begin{array}{l}4 \text { amino acids } \\
\text { inserted }\end{array}$ \\
\hline \multirow[t]{8}{*}{ DVU2395 } & EN4 & Deletion & 100 & 2499096 & -8: CGGCGAGC & Frameshift mutation \\
\hline & \multirow[t]{2}{*}{ EN8 } & \multirow[t]{2}{*}{ Insertion } & 46 & 2498544 & $+2: \mathrm{CG}$ & $\begin{array}{l}4 \text { amino acids } \\
\text { changed }\end{array}$ \\
\hline & & & 26 & 2499078 & +14:CCTCATGCGCCACC & Frameshift mutation \\
\hline & EN9 & Deletion & 54 & 2499384 & $-1: \mathrm{T}$ & Frameshift mutation \\
\hline & \multirow[t]{3}{*}{ EN10 } & SNP & 15 & 2498363 & $\mathrm{~T} \rightarrow \mathrm{C}$ & Silent mutation \\
\hline & & SNP & 23 & 2498737 & $\mathrm{~T} \rightarrow \mathrm{C}$ & Lys $\rightarrow$ Glu \\
\hline & & SNP & 45 & 2498935 & $\mathrm{G} \rightarrow \mathrm{A}$ & Gln $\rightarrow$ STOP \\
\hline & EN12 & SNP & 100 & 2499244 & $\mathrm{G} \rightarrow \mathrm{A}$ & Gln $\rightarrow$ STOP \\
\hline \multirow[t]{4}{*}{ DVU2396 } & \multirow[t]{2}{*}{ EN1 } & SNP & 20 & 2499926 & $\mathrm{G} \rightarrow \mathrm{A}$ & Pro $\rightarrow$ Ser \\
\hline & & SNP & 72 & 2500012 & $\mathrm{G} \rightarrow \mathrm{T}$ & Ser $\rightarrow$ STOP \\
\hline & EN2 & Deletion & 98 & 2499984 & $-1: \mathrm{C}$ & Frameshift mutation \\
\hline & EN6 & Deletion & 42 & 2499735 & $-1: \mathrm{C}$ & Frameshift mutation \\
\hline DVU2402 & EN2 & SNP & 96 & 2507986 & $\mathrm{G} \rightarrow \mathrm{A}$ & Arg $\rightarrow$ Cys \\
\hline \multirow[t]{3}{*}{ DVU2405 } & EN5 & SNP & 81 & 2510695 & $\mathrm{C} \rightarrow \mathrm{A}$ & Glu $\rightarrow$ STOP \\
\hline & \multirow[t]{2}{*}{ EN11 } & Deletion & 100 & 2510695 & $-1: \mathrm{C}$ & Frameshift mutation \\
\hline & & SNP & 100 & 2510695 & $\mathrm{C} \rightarrow \mathrm{T}$ & Glu $\rightarrow$ Lys \\
\hline
\end{tabular}

\section{Deletion mutants of NSR and NRC genes resulted in improved nitrate tolerance}

To determine if nonsense and frameshift mutations are involved in nitrate tolerance in EN populations and to understand possible nitrate tolerance mechanisms in $\mathrm{DvH}$, we generated representative deletion mutants of NRC and NSR genes, and analyzed their growth under elevated nitrate, $\mathrm{NaCl}$, or nitrite. The NSR group includes three genes: $h c p$ (hybrid cluster protein, DVU2543), $h c p R$ (hcp regulator, DVU2547) and $a c p D$ (DVU2548) (Table 2). DVU2547 encoding HcpR was one of the most frequently mutated genes in seven out of 12 EN populations (Table 3). Also, these mutations were identified in key domains of $h c p R$ (DVU2547), including DNA-binding domain (EN1-1, EN1-2), cAMP-binding domain (EN1-2), and dimer interface (EN3-1, EN3-2, EN6, EN9) (Fig. S3), and the same nonsense SNP was fixed in EN7 and nearly fixed in EN8. Analysis of those mutants indicated that the growth of parental strain JZ001 and NSR gene deletion mutants was quite similar without nitrate or nitrite addition (Fig. 2a), but these mutants grew faster than JZ001 with $0.15 \mathrm{mM}$ nitrite added although a lower final biomass was obtained for the mutants (Fig. 2b). Especially, when 30 $\mathrm{mM}$ was added, all three mutants had shorter lag phases, higher growth rates, and higher biomass yield than JZ001 $(p<0.05)$, indicating increased nitrate tolerance in those mutants (Fig. 2c). In addition, a similar growth was observed for JZ001P (JZ001 with empty vector pMO719) and the complemented strains (ME2543 and ME2547) without nitrate (data not shown), while decreased nitrate tolerance was observed in the complemented strains (Fig. 2d) and EN7 variant (Fig. S4) under elevated nitrate, possibly due to the overexpression of complemented genes. It is noted that we could not obtain a complemented strain for ME2548 after several attempts. The results demonstrated that nonsense and frameshift mutations in the NSR group (Table 3) could improve nitrate tolerance in EN populations.

NRC group contains a two component system DVU2394 (Response Regulator, RR)/DVU2395 (Histidine Kinase, HK), which regulates the expression of operon DVU2397-2405 encoding alcohol dehydrogenase and heterodisulfide reductase (Table 2). Marker exchange (ME) mutants of DVU2394, 
Table 5 Newly acquired mutations in nitrate cluster in the EN populations.

\begin{tabular}{|c|c|c|c|c|c|c|}
\hline Gene & Populations & Mutation type & $\begin{array}{l}\text { Allele } \\
\text { frequency }(\%)\end{array}$ & $\begin{array}{l}\text { Mutation } \\
\text { position }\end{array}$ & Nucleotide change & Amino-acid change \\
\hline \multirow{7}{*}{ DVU0246 } & EN1 & Deletion & 77 & 279997 & $\mathrm{AGG} \rightarrow \mathrm{AG}$ & Frameshift mutation \\
\hline & EN2 & Deletion & 15 & 279123 & $\mathrm{CG} \rightarrow \mathrm{G}$ & Frameshift mutation \\
\hline & & Deletion & 53 & 279997 & $\mathrm{AGG} \rightarrow \mathrm{AG}$ & Frameshift mutation \\
\hline & EN7 & Deletion & 48 & 279074 & -234 bp & Frameshift mutation \\
\hline & EN8 & Deletion & 21 & 280374 & -11: TGTTGCCGTCG & Frameshift mutation \\
\hline & EN9 & SNP & 59 & 279507 & $\mathrm{C} \rightarrow \mathrm{A}$ & Gly $\rightarrow$ STOP \\
\hline & EN11 & Deletion & 48 & 279702 & $\mathrm{GT} \rightarrow \mathrm{G}$ & Frameshift mutation \\
\hline \multirow[t]{2}{*}{ DVU0247 } & EN6 & Deletion & 34 & 281155 & $\mathrm{AT} \rightarrow \mathrm{A}$ & Frameshift mutation \\
\hline & & Insertion & 50 & 281286 & $+4:$ ACGA & Frameshift mutation \\
\hline \multirow[t]{7}{*}{ DVU0248 } & EN3 & Deletion & 14 & 281561 & $\mathrm{AGG} \rightarrow \mathrm{AG}$ & Frameshift mutation \\
\hline & EN4 & SNP & 63 & 283154 & $\mathrm{C} \rightarrow \mathrm{T}$ & Asp $\rightarrow$ Asn \\
\hline & EN5 & Deletion & 18 & 281703 & $\mathrm{GT} \rightarrow \mathrm{G}$ & Nonsense mutation \\
\hline & EN8 & SNP & 65 & 282788 & $\mathrm{C} \rightarrow \mathrm{T}$ & $\mathrm{Ala} \rightarrow \mathrm{Thr}$ \\
\hline & EN9 & Deletion & 14 & 293167 & $-63 b p$ & Frameshift mutation \\
\hline & EN10 & SNP & 18 & 283136 & $\mathrm{C} \rightarrow \mathrm{T}$ & Gly $\rightarrow$ Arg \\
\hline & EN12 & SNP & 47 & 283204 & $\mathrm{G} \rightarrow \mathrm{T}$ & Ser $\rightarrow$ Tyr \\
\hline DVU0249 & EN3 & SNP & 17 & 283782 & $\mathrm{C} \rightarrow \mathrm{T}$ & Gly $\rightarrow$ Asp \\
\hline \multirow[t]{5}{*}{ DVU0251 } & EN3 & SNP & 13 & 285479 & $\mathrm{G} \rightarrow \mathrm{A}$ & $\mathrm{Thr} \rightarrow$ Ile \\
\hline & & SNP & 19 & 285947 & $\mathrm{C} \rightarrow \mathrm{G}$ & Gly $\rightarrow$ Ala \\
\hline & & SNP & 13 & 286439 & $\rightarrow \mathrm{T}$ & $\begin{array}{l}109 \text { bases upstream of the } \\
\text { start codon }\end{array}$ \\
\hline & EN7 & SNP & 33 & 285948 & $\mathrm{C} \rightarrow \mathrm{T}$ & Gly $\rightarrow$ Ser \\
\hline & EN12 & SNP & 23 & 285948 & $\mathrm{C} \rightarrow \mathrm{T}$ & Gly $\rightarrow$ Ser \\
\hline \multirow{3}{*}{$\begin{array}{l}\text { DVU0246- } \\
0251\end{array}$} & EN5 & Deletion & 28 & 279540 & -9920 bp & $\Delta$ DVU0246-0251 \\
\hline & EN10 & & 33 & 279032 & $-15883 b p$ & \\
\hline & EN12 & & 32 & 272887 & $-38514 b p$ & \\
\hline $\begin{array}{l}\text { DVU0250- } \\
0251\end{array}$ & EN5 & Deletion & 27 & 284766 & $-5814 b p$ & $\Delta$ DVU0250-0251 \\
\hline
\end{tabular}

DVU2395, DVU2396, and DVU2405 in the NRC group were generated. While no significant growth differences were observed between ME mutants and JZ001 in LS4D (Fig. 3a) or LS4D with $100 \mathrm{mM} \mathrm{NaCl}$ (Fig. 3b), all NRC mutants had higher growth rates $(p<0.05)$ in LS4D amended with $30 \mathrm{mM}$ nitrate except ME2405, which had the shortest lag phase compared to both JZ001 and other ME mutants (Fig. 3c). As expected, the parental strain (with empty plasmid pMO719)like phenotypes were observed for all complemented strains of NRC mutants (Fig. 3d). The results confirmed that nonsense and frameshift mutations in the NRC gene group (Table 4) likely led to increased nitrate tolerance in EN populations.

\section{Discussion}

Experimental evolution coupled with whole-genome resequencing enable us to link genotype with phenotype, understand nitrate tolerance mechanisms, and facilitate the advancement of our knowledge about SRB responses to elevated nitrate in the environment. In this study, we found that most newly acquired mutations occurred in six gene groups of DvH through experimental evolution under elevated nitrate, and deletion mutants of NSR and NRC genes confirmed their roles in nitrate tolerance, indicating that those nonsense and frameshift mutations were beneficial. Also, identical or similar mutations were observed in EN populations evolved independently, suggesting genetic parallelism of adaptive selection at the population level.

Beneficial mutations in stress-evolved populations are considered as drivers of adaptation [21, 32]. Previous studies of adaptive evolution in Desulfovibrio species showed beneficial mutations emerged along the experimental evolution and conferred a fitness advantage under stress conditions $[23,36]$. In this study, we found a set of high-frequency mutations in six gene groups of EN populations, and they conferred nitrate tolerance in $\mathrm{DvH}$, appearing to be beneficial. 
Fig. 2 Growth phenotype of DvH parental strain (JZ001) and marker exchange mutants (ME2543, ME2547 and ME2548) of nitrosative stress response genes (NSR). (a) no stress (LS4D); (b) nitrite stress $(\mathrm{LS} 4 \mathrm{D}+0.15 \mathrm{mM} \mathrm{NaNO})_{2} ;(\mathbf{c})$ nitrate stress (LS4D + $30 \mathrm{mM}$ $\mathrm{NaNO}_{3}$ ); and (d) the growth phenotype of complemented mutants with extra $30 \mathrm{mM}$ $\mathrm{NaNO}_{3}$ in the medium. JZ001P: JZ001 with empty vector pMO719; ME2543(C): the complemented strain of ME2543; ME2547(C): the complemented strain of ME2547. The complemented strain for ME2548 was not obtained.
Fig. 3 Growth phenotype of DvH parental strain (JZ001) and marker exchange mutants (ME2394, ME2395, ME2396, and ME2405) of nitrogen regulatory protein family $\mathrm{C}$ genes (NRC). (a) no stress (LS4D); (b) salt stress (LS4D + $100 \mathrm{mM} \mathrm{NaCl}$ ); (c) nitrate stress (LS4D + $30 \mathrm{mM} \mathrm{NaNO}$ ); and (d) the growth phenotype of complemented mutants with extra $30 \mathrm{mM} \mathrm{NaNO}_{3}$ in the medium. JZ001P: JZ001 with empty vector pMO719; ME2394 (C): the complemented strain of ME2394; ME2395(C): the complemented strain of ME2395; ME2396(C): the complemented strain of ME2396; ME2405(C): the complemented strain of ME2405.
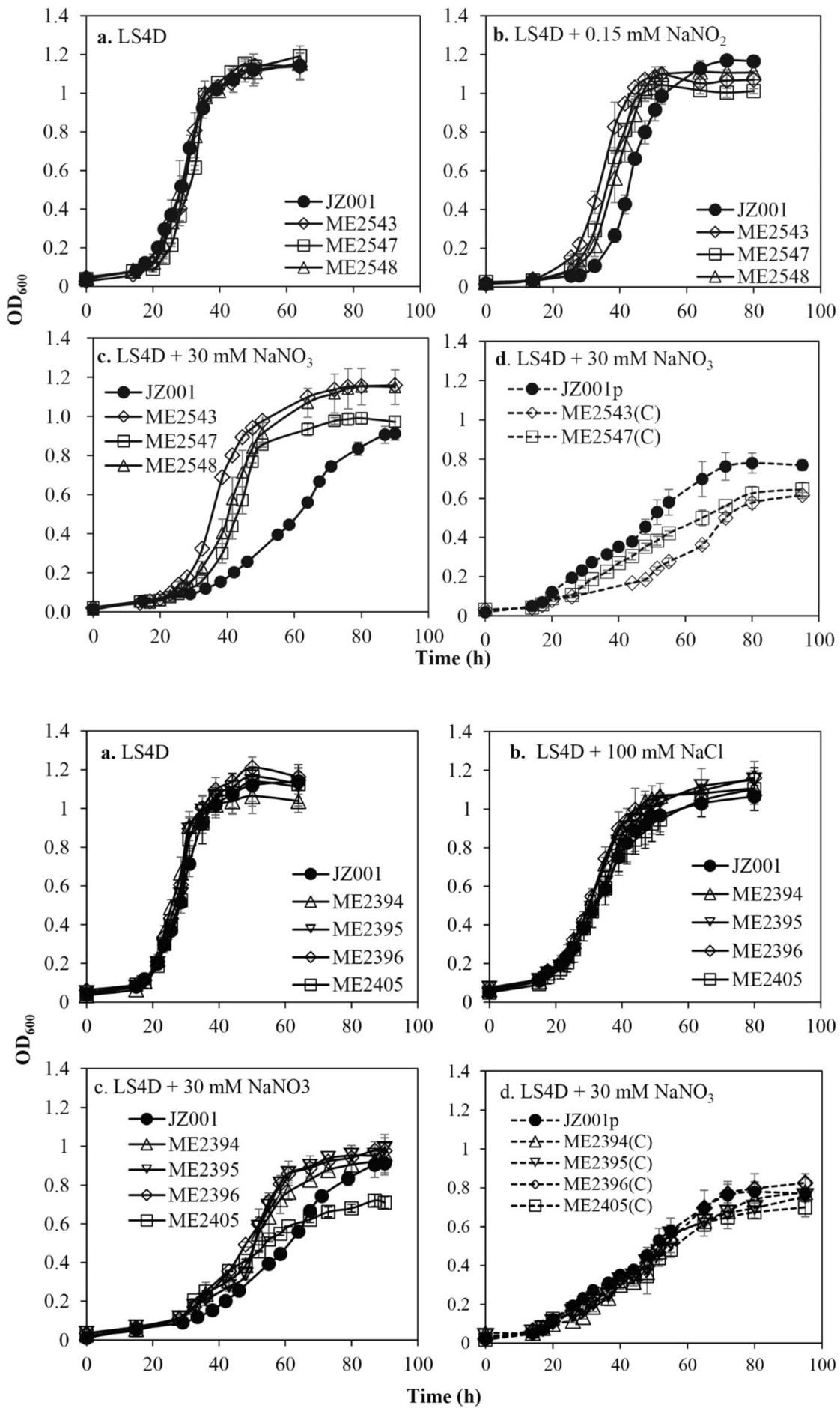

However, native functions of those gene groups are not likely involved with nitrate metabolism but largely by gene regulations, such as three two-component systems (DVU2394/ DVU2395, DVU0596/DVU0597, and DVU0246/DVU0247) and two global transcriptional regulators/regulons (DVU2547/ DVU2543 and DVU0942/DVU2571) [14, 18, 52-54]. Those regulatory systems may perceive nitrate stress and control downstream responses, and based on functions of mutated genes and the fact that no nitrate was consumed, our results suggest that adaptive mechanisms of DvH under elevated nitrate may include (i) shifting of energy metabolism, (ii) barring entry of nitrate into the cell, (iii) altering cell membrane characteristics, and (iv) conferring growth advantages at the stationary (GASP) phase.

First, a shift of energy metabolism could provide physiological advantages for DvH to survive nitrate stress [4], 


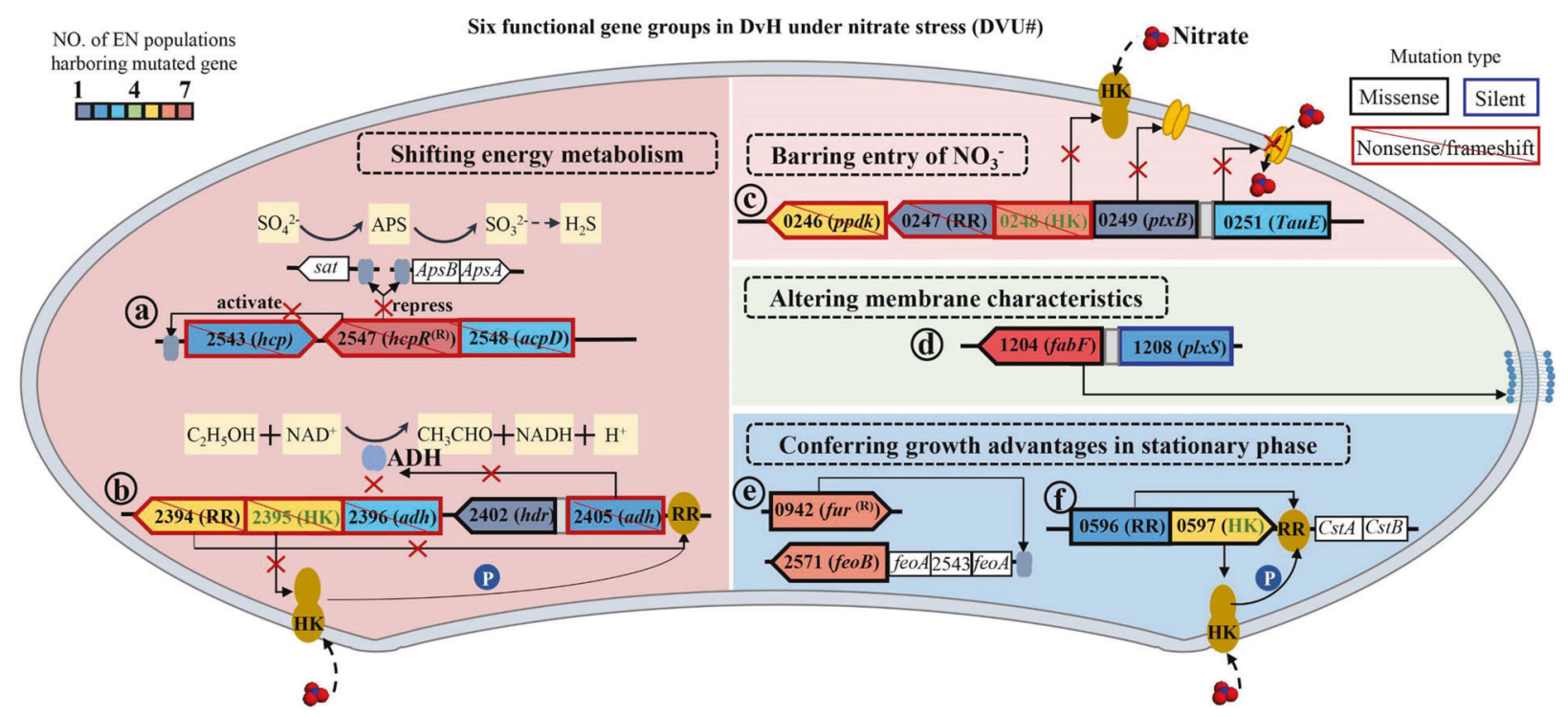

Fig. 4 A schematic representation of possible nitrate tolerance mechanisms in DvH. Frequently mutated genes were clustered into six groups (DVU\#), including (a) nitrosative stress response (NSR) genes, (b) nitrogen regulation protein $\mathrm{C}$ family (NRC) genes, (c) nitrate cluster, (d) fatty acid synthesis genes, (e) iron regulatory genes, and (f) two component system LytR/LytS. Nonsense and frameshift mutations were identified in the first three gene groups $(\mathbf{a}, \mathbf{b}$, and $\mathbf{c})$, indicating that a functional loss of some of those genes/groups conferred nitrate tolerance in DvH. Possible mechanisms for increased nitrate tolerance may include a shift of energy metabolism through derepression of sulfate reduction (a), lacking alcohol oxidation

thus increasing nitrate tolerance after experimental evolution. A previous study indicated that a deletion mutant of DVU0916 (rex), a repressor of sulfate adenylyl transferase increased nitrate tolerance [18]. We found that a large number of mutations were identified in NSR and NRC genes involved in energy metabolism, and functional loss of those genes conferred nitrate tolerance. DVU2547 ( $h c p R$ ) of NSR was proposed to be involved in energy metabolism through repressing sulfate reduction pathways and activating expression of DVU2543 ( $h c p$ ), which responds to reactive nitrogen species and was up-regulated under elevated nitrite or nitrate [4, 55-57]. A possible explanation for growth advantages of an $h c p R$ mutation was suggested to be derepression of sulfate-reducing genes resulting from the loss of the repressor HcpR (Fig. 4a). Also, we found NRC genes conferred nitrate tolerance, which has not been reported before. In this gene group, DVU2405 (alcohol dehydrogenase, $a d h$ ) regulated by a two-component system (DVU2394/DVU2395) was shown to be one of the most highly expressed genes contributing to energy metabolism with different electron donors in DvH [58]. Thus functional loss of genes in the NRC group may lead to a shift to methyl/S-adenosyl-methionine metabolism due to a lack of alcohol oxidation pathways catalyzed by alcohol dehydrogenase encoded by DVU2405 [4, 58] (Fig. 4b). Our pathways catalyzed by alcohol dehydrogenase (b), barring entry of nitrate into cell by (c) [18], altering overall membrane characteristics (d) [23, 62], and conferring growth advantages by regulating iron homeostasis (e) and carbon metabolism (carbon starvation genes CstA and $C s t B)(\mathbf{f})$ at the stationary phase [66]. Dashed boxes represent possible nitrate tolerance mechanisms. Key genes were confirmed by mutagenesis analysis for their contribution to nitrate tolerance $(\mathbf{a}, \mathbf{b})$, and arrows represent processes demonstrated by previous studies $[18,23,52,56,66]$. ADH alcohol dehydrogenase, HK sensor histidine kinase, RR response regulator, ${ }^{(}$phosphoryl group, gene ${ }^{(\mathrm{R})}$ global transcriptional regulator.

results suggested that those frameshift and nonsense mutations in the NSR and NRC gene groups could relieve nitrate stress through shifting energy metabolisms, and those new findings advance our understanding the role of NSR and NRC groups in nitrate tolerance in DvH.

Second, blocking nitrate entry into the cell could confer nitrate tolerance in DvH. The nitrate cluster genes were proposed to allow non-specific nitrate transport, while transposon mutants of nitrate cluster genes were found to have a growth advantage under nitrate stress [18]. Also, DVU0249 encodes an outer membrane-associated homodimer [59], and DVU0251 is a TauE like transmembrane protein [18]. Therefore, we speculate that those nitrate cluster genes may be involved in nitrate uptake or transport, and the functional loss of those genes may prevent nitrate entry into the DvH cell [18], which is consistent with our study, showing that nonsense and frameshift mutations occurred in nitrate cluster (Fig. 4c).

Third, altering membrane lipid composition is crucial for bacterial survival and adaptation under environmental stresses [60]. Membrane fatty acid synthesis was shown to be involved in heat stress, salt stress, and oxidative stress adaptation in E.coli [61]. Previous studies also indicated that the percentage of unsaturated fatty acid in cell membrane was affected under salt stress, while the formation of 
acyl-accepter was catalyzed by DVU1204 ( $a b F)$, a possible essential gene in DvH [23, 62], and it was up-regulated under heat stress [63]. We found that the gene $f a b F$ was high-frequently mutated in EN populations, which could increase unsaturated fatty acid percentages in cell membrane, thus increasing nitrate tolerance possibly by relieving osmotic stress (Fig. 4d).

Fourth, GASP could be beneficial for bacteria to adapt to different stresses due to competitive ability conferred by GASP mutations (e.g., in the gene rpoS) emerged during a long-term stationary phase [64]. A previous study with $E$. coli indicated the transcriptional regulator RpoS exhibited GASP mutations and responded to multiple stresses [65]. However, DvH does not have an annotated rpoS gene. Alternatively, iron homeostasis maintained by DVU2571 $(f e o B)$ and up-regulation of DVU0598 and DVU0599 encoding carbon starvation proteins regulated by lytR/lytS, which suggested being involved in stresses response as DvH cells transitioned into the stationary phase [66]. Furthermore, DVU2571 and lytR/lytS were also mutated in serial transfers with or without salt stress [23]. Such an experimental evolution may emerge mutations in those genes up-regulated at the stationary phase, as evolved $\mathrm{DvH}$ populations were kept at the stationary phase for $\sim 24 \mathrm{~h}$ in every transfer $(48 \mathrm{~h})$. In this case, it is reasonable to assume that newly acquired mutations in those GASP-related genes may increase nitrate tolerance through relieving possible environmental stresses like nutrient depletion (Fig. 4e, f).

Notably, some beneficial mutations occurred in evolved populations may just increase the overall growth (e.g., shortened lag phase, increased growth rate, increased biomass) without direct effects for a specific stress during an experimental evolution [67]. For example, our previous study showed that a mutation in DVU0597 was related to increased growth and biomass as well as shortened lag phase while another mutation in DVU2472 was related to increased biomass and shortened lag phase in salt-evolved populations of DvH [23]. In this study, we found shortened lag phase and increased growth rate for EN populations with or without nitrate stress, which is similar to a previous study, showing that both control-evolved populations (EC) and salt-evolved populations (ES) had a shorter lag phase with or without salt stress compared to their ancestral populations (without evolution) in DvH [37]. Also, a few shared mutated genes (DVU1204, DVU2571, and DVU0596/DVU0597) were found in those populations (EN, EC, and ES), which may confer an increase of general stress tolerance $[23,60,62-64,66]$. Furthermore, the fact that high concentrations of iron could be regulated by DVU2571 during the lag phase emphasized the role of iron accumulation in the early stage of bacterial growth [68]. Therefore, our results highlighted potential roles of general stress response genes, especially GASP associated genes
(DVU0597 and DVU2571) in promoting the overall growth in EN populations.

In addition, parallel genetic changes were observed at the mutation, gene, and gene group levels in independent populations. At the mutation level (identical mutations among EN populations), identical mutations were observed in six gene groups and other less defined genes, and they were nearly fixed or fixed. For example, identical nonsense and frameshift mutations occurred in the NSR gene or the nitrate cluster of independent EN populations, resulting in truncated proteins and increased nitrate resistance. Identical fixed or nearly fixed missense mutations were also observed at the coordinate 1034711 in DVU0924 in EN4, EN5, and EN9 (Tables S3 and S8). At the gene level (different mutations in the same gene across EN populations), nonsense and frameshift mutations were observed for genes in the NSR, NRC, and nitrate cluster, which may result in nonfunctional proteins and similar phenotypic changes that conferred nitrate tolerance. Moreover, parallel genetic changes were also reflected at the gene group level (genetic changes occurred in functional gene groups of independent populations), leading to similar phenotypic shifts, especially in NSR, NRC, and nitrate cluster. For example in the NRC group, loss-of-function mutations were identified in DVU2394 (RR) in EN5 and EN9, in DVU2395 (HK) in EN5, EN9, EN10, and EN12, in DVU2396 in EN1, EN2, and EN6, indicating that these genetic changes were similar and contributed to nitrate tolerance in independent populations. Notably, in this study, parallel evolution was more likely to happen via loss-of-function mutations. Therefore, such genetic parallelism involved in SNP/INDELs coupled with their high allele frequencies under elevated nitrate may be largely beneficial mutations in EN populations.

In summary, this study reveals nitrate tolerance mechanisms largely associated with six gene groups by experimental evolution in DvH. When DvH was exposed to elevated nitrate for 1000 generations, a number of beneficial mutations occurred. Nonsense and frameshift mutations were identified in NSR, NRC and nitrate clusters, resulting in increased nitrate tolerance through regulating energy metabolism and barring entry of nitrate into DvH cells, while missense mutations in fatty acid synthesis genes, iron regulatory genes, and lytR/lytS may confer general stress tolerance by experimental evolution under elevated nitrate through altering cell membrane characteristics and conferring GASP. Also, genetic parallelism is reflected at the mutation, gene, and gene group levels, allowing us to further understand DvH responses to elevated nitrate. This study unravels genetic basis of evolutionary changes in nitrate-evolved populations and provides a comprehensive understanding of nitrate tolerance mechanisms, which has important implications for linking genotypes with phenotypes in DvH. Future studies may further understand 
possible indirect nitrate tolerance mechanisms using a coinciding evolved control without additional nitrate and explore the contribution of important individual mutations and other highly mutated genes to nitrate tolerance in EN populations.

Acknowledgements The experimental work of this study (October 2013 to June 2017) was largely supported by ENIGMA-Ecosystems and Networks Integrated with Genes and Molecular Assemblies (http://enigma.lbl.gov), a Science Focus Area Program at Lawrence Berkeley National Laboratory is based upon work supported by the U. S. Department of Energy, Office of Science, and Office of Biological \& Environmental Research under contract number DE-AC0205CH11231, the Office of the Vice President for Research at the University of Oklahoma (JZ), and the National Program on Key Basic Research Project of China (973 Program, No. 2015CB150505 to SC); the subsequent integration work (October 2018 to March 2020) of this study, including supplementary experiments, data analysis and manuscript writing, was mainly supported by the National Natural Science Foundation of China (Grant numbers 31770539 and 91951207 to $\mathrm{ZH}$, grant number 31672262 to QY), and the Special Funds for Scientific and Technological Innovation in Guangdong Province (Grant number 2018A030310302 to BW).

\section{Compliance with ethical standards}

Conflict of interest The authors declare that they have no conflict of interest.

Publisher's note Springer Nature remains neutral with regard to jurisdictional claims in published maps and institutional affiliations.

\section{References}

1. Zhou JZ, He Q, Hemme CL, Mukhopadhyay A, Hillesland K, Zhou AF, et al. How sulphate-reducing microorganisms cope with stress: lessons from systems biology. Nat Rev Microbiol. 2011;9:452-66.

2. Bowles MW, Mogollon JM, Kasten S, Zabel M, Hinrichs KU, Global rates of marine sulfate reduction and implications for subsea-floor metabolic activities. Science. 2014;344:889-91.

3. Plugge CM, Zhang W, Scholten JC, Stams AJ. Metabolic flexibility of sulfate-reducing bacteria. Front Microbiol. 2011;2:81.

4. He Q, He Z, Joyner DC, Joachimiak M, Price MN, Yang ZK, et al. Impact of elevated nitrate on sulfate-reducing bacteria: a comparative study of Desulfovibrio vulgaris. ISME J. 2010;4:1386-97.

5. Kamp A, Hogslund S, Risgaard-Petersen N, Stief P. Nitrate storage and dissimilatory nitrate reduction by eukaryotic microbes. Front Microbiol. 2015;6:1492.

6. Hubert C, Voordouw G. Oil field souring control by nitratereducing Sulfurospirillum spp. that outcompete sulfate-reducing bacteria for organic electron donors. Appl Environ Microbiol. 2007;73:2644-52.

7. Canter LW. Nitrates in groundwater, Routledge, Abingdon, 2019.

8. Ascott MJ, Gooddy DC, Wang L, Stuart ME, Lewis MA, Ward RS, et al. Global patterns of nitrate storage in the vadose zone. Nat Commun. 2017;8:1416.

9. Green SJ, Prakash O, Jasrotia P, Overholt WA, Cardenas E, Hubbard D, et al. Denitrifying bacteria from the genus rhodanobacter dominate bacterial communities in the highly contaminated subsurface of a nuclear legacy waste site. Appl Environ Microbiol. 2012;78:1039-47.
10. Hubert C. Microbial ecology of oil reservoir souring and its control by nitrate injection. Springer:Berlin,Germany; 2010. p. 2753-66.

11. Suri N, Voordouw J, Voordouw G. The effectiveness of nitratemediated control of the oil field sulfur cycle depends on the toluene content of the oil. Front Microbiol. 2017;8:956.

12. ECHET Lucassen, Smolders AJP, Van der Salm AL, Roelofs JGM. High groundwater nitrate concentrations inhibit eutrophication of sulphate-rich freshwater wetlands. Biogeochemistry. 2004;67:249-67.

13. Marietou A. Nitrate reduction in sulfate-reducing bacteria. FEMS Microbiol Lett. 2016;363:fnw155.

14. Cadby IT, Ibrahim SA, Faulkner M, Lee DJ, Browning D, Busby SJ, et al. Regulation, sensory domains and roles of two Desulfovibrio desulfuricans ATCC27774 Crp family transcription factors, HcpR1 and HcpR2, in response to nitrosative stress. Mol Microbiol. 2016;102:1120-37.

15. Haveman SA, Greene EA, Voordouw G. Gene expression analysis of the mechanism of inhibition of Desulfovibrio vulgaris Hildenborough by nitrate-reducing, sulfide-oxidizing bacteria. Environ Microbiol. 2005;7:1461-5.

16. Callbeck CM, Agrawal A, Voordouw G. Acetate production from oil under sulfate-reducing conditions in bioreactors injected with sulfate and nitrate. Appl Environ Microbiol. 2013;79:5059-68.

17. Redding AM, Mukhopadhyay A, Joyner DC, Hazen TC, Keasling JD. Study of nitrate stress in Desulfovibrio vulgaris Hildenborough using iTRAQ proteomics. Brief Funct Genomic Proteomic. 2006;5:133-43.

18. Korte HL, Fels SR, Christensen GA, Price MN, Kuehl JV, Zane GM, et al. Genetic basis for nitrate resistance in Desulfovibrio strains. Front Microbiol. 2014;5:153.

19. Korte HL, Saini A, Trotter VV, Butland GP, Arkin AP, Wall JD. Independence of nitrate and nitrite inhibition of Desulfovibrio vulgaris Hildenborough and use of nitrite as a substrate for growth. Environ Sci Technol. 2014;49:924-31.

20. Elena SF, Lenski RE. Evolution experiments with microorganisms: the dynamics and genetic bases of adaptation. Nat Rev Genet. 2003;4:457-69.

21. Lenski RE. Experimental evolution and the dynamics of adaptation and genome evolution in microbial populations. ISME J. 2017;11:2181.

22. Barrick JE, Lenski RE. Genome dynamics during experimental evolution. Nat Rev Genet. 2013;14:827-39.

23. Zhou A, Hillesland KL, He Z, Schackwitz W, Tu Q, Zane GM, et al. Rapid selective sweep of pre-existing polymorphisms and slow fixation of new mutations in experimental evolution of Desulfovibrio vulgaris. ISME J. 2015;9:2360-72.

24. Adams J, Rosenzweig F. Experimental microbial evolution: history and conceptual underpinnings. Genomics. 2014;104:393-8.

25. van Ditmarsch D, Boyle KE, Sakhtah H, Oyler JE, Nadell CD, Deziel E, et al. Convergent evolution of hyperswarming leads to impaired biofilm formation in pathogenic bacteria. Cell Rep. 2013;4:697-708.

26. Gerstein AC, Chun HJE, Grant A, Otto SP. Genomic convergence toward diploidy in Saccharomyces cerevisiae. PLoS Genet. 2006;2:1396-401.

27. Kerr B, Neuhauser C, Bohannan BJ, Dean AM. Local migration promotes competitive restraint in a host-pathogen 'tragedy of the commons'. Nature. 2006;442:75-78.

28. Burch CL, Chao L. Evolution by small steps and rugged landscapes in the RNA Virus $\phi 6$. Genetics. 1999;151:921-7.

29. Levy SF, Blundell JR, Venkataram S, Petrov DA, Fisher DS, Sherlock G. Quantitative evolutionary dynamics using highresolution lineage tracking. Nature. 2015;519:181.

30. Bell G. Evolutionary rescue of a green alga kept in the dark. Biol Lett. 2013;9:20120823. 
31. Stern DL. The genetic causes of convergent evolution. Nat Rev Genet. 2013;14:751-64.

32. Tenaillon O, Barrick JE, Ribeck N, Deatherage DE, Blanchard JL, Dasgupta A, et al. Tempo and mode of genome evolution in a 50,000-generation experiment. Nature. 2016;536:165.

33. Tenaillon $\mathrm{O}$, Rodriguez-Verdugo A, Gaut RL, McDonald $\mathrm{P}$, Bennett AF, Long AD, et al. The molecular diversity of adaptive convergence. Science. 2012;335:457-61.

34. Vogwill T, Phillips RL, Gifford DR, MacLean RC. Divergent evolution peaks under intermediate population bottlenecks during bacterial experimental evolution. $\mathrm{P}$ Roy Soc B-Biol Sci. 2016;283:20160749.

35. Cooper VS, Schneider D, Blot M, Lenski RE. Mechanisms causing rapid and parallel losses of ribose catabolism in evolving populations of Escherichia coli B. J Bacteriol. 2001;183:2834-41.

36. Mehta-Kolte MG, Stoeva MK, Mehra A, Redford SA, Youngblut MD, Zane G, et al. Adaptation of Desulfovibrio alaskensis G20 to perchlorate, a specific inhibitor of sulfate reduction. Environ Microbiol. 2019;21:1395-406.

37. Zhou A, Baidoo E, He Z, Mukhopadhyay A, Baumohl JK, Benke $\mathrm{P}$, et al. Characterization of $\mathrm{NaCl}$ tolerance in Desulfovibrio vulgaris Hildenborough through experimental evolution. ISME J. 2013;7:1790-802.

38. Mukhopadhyay A, He Z, Alm EJ, Arkin AP, Baidoo EE, Borglin SC, et al. Salt stress in Desulfovibrio vulgaris Hildenborough: an integrated genomics approach. J Bacteriol. 2006;188:4068-78.

39. Kong Y. Btrim: a fast, lightweight adapter and quality trimming program for next-generation sequencing technologies. Genomics. 2011;98:152-3.

40. Langmead B, Salzberg SL. Fast gapped-read alignment with Bowtie 2. Nat Methods. 2012;9:357.

41. Li H, Handsaker B, Wysoker A, Fennell T, Ruan J, Homer N, et al. The sequence alignment/map format and SAMtools. Bioinformatics. 2009;25:2078-9.

42. Narasimhan V, Danecek P, Scally A, Xue YL, Tyler-Smith C, Durbin R. BCFtools/RoH: a hidden Markov model approach for detecting autozygosity from next-generation sequencing data. Bioinformatics. 2016;32:1749-51.

43. Deatherage DE, Barrick JE. Identification of mutations in laboratory-evolved microbes from next-generation sequencing data using breseq. In: Sun L, Shou W (eds). Engineering and analyzing multicellular systems: methods and protocols. Springer New York: New York, NY; 2014. pp. 165-88.

44. Good BH, McDonald MJ, Barrick JE, Lenski RE, Desai MM. The dynamics of molecular evolution over 60,000 generations. Nature. 2017;551:45-50.

45. Heidelberg JF, Seshadri R, Haveman SA, Hemme CL, Paulsen IT, Kolonay JF, et al. The genome sequence of the anaerobic, sulfatereducing bacterium Desulfovibrio vulgaris Hildenborough. Nat Biotechnol. 2004;22:554-9.

46. Szklarczyk D, Morris JH, Cook H, Kuhn M, Wyder S, Simonovic $M$ et al. The STRING database in 2017: quality-controlled protein-protein association networks, made broadly accessible. Nucleic Acids Res. 2017;45:D362-8.

47. Pelley JW. Protein synthesis and degradation. In: Pelley JW (ed). Elsevier's Integrated Review Biochemistry (Second Edition). W. B. Saunders, Philadelphia: 2012, pp. 149-60.

48. Kelley LA, Mezulis S, Yates CM, Wass MN. The Phyre2 web portal for protein modeling, prediction and analysis. Nat Protoc. 2015;10:845-58.

49. Keller KL, Bender KS, Wall JD. Development of a markerless genetic exchange system for Desulfovibrio vulgaris Hildenborough and its use in generating a strain with increased transformation efficiency. Appl Environ Microbiol. 2009;75:7682-91.

50. Aragao D, Macedo S, Mitchell EP, Romao CV, Liu MY, Frazao C, et al. Reduced hybrid cluster proteins (HCP) from Desulfovibrio desulfuricans ATCC 27774 and Desulfovibrio vulgaris (Hildenborough): $\mathrm{X}$-ray structures at high resolution using synchrotron radiation. J Biol Inorg Chem. 2003;8:540-8.

51. Price MN, Huang KH, Alm EJ, Arkin AP. A novel method for accurate operon predictions in all sequenced prokaryotes. Nucleic Acids Res. 2005;33:880-92.

52. Rajeev L, Luning EG, Dehal PS, Price MN, Arkin AP, Mukhopadhyay A. Systematic mapping of two component response regulators to gene targets in a model sulfate reducing bacterium. Genome Biol. 2011;12:R99.

53. Bender KS, Yen HC, Hemme CL, Yang Z, He Z, He Q, et al. Analysis of a ferric uptake regulator (Fur) mutant of Desulfovibrio vulgaris Hildenborough. Appl Environ Microbiol. 2007;73:5389-400.

54. Zhou A, Chen YI, Zane GM, He Z, Hemme CL, Joachimiak MP, et al. Functional characterization of Crp/Fnr-type global transcriptional regulators in Desulfovibrio vulgaris Hildenborough. Appl Environ Microbiol. 2012;78:1168-77.

55. He Q, Huang KH, He Z, Alm EJ, Fields MW, Hazen TC, et al. Energetic consequences of nitrite stress in Desulfovibrio vulgaris Hildenborough, inferred from global transcriptional analysis. Appl Environ Microbiol. 2006;72:4370-81.

56. Rodionov DA, Dubchak I, Arkin A, Alm E, Gelfand MS. Reconstruction of regulatory and metabolic pathways in metalreducing delta-proteobacteria. Genome Biol. 2004;5:R90.

57. Cadby IT, Busby SJ, Cole JA. An HcpR homologue from Desulfovibrio desulfuricans and its possible role in nitrate reduction and nitrosative stress. Biochem Soc Trans. 2011;39:224-9.

58. Haveman SA, Brunelle V, Voordouw JK, Voordouw G, Heidelberg JF, Rabus R. Gene expression analysis of energy metabolism mutants of Desulfovibrio vulgaris Hildenborough indicates an important role for alcohol dehydrogenase. J Bacteriol. 2003; 185:4345-53.

59. Walian PJ, Allen S, Shatsky M, Zeng L, Szakal ED, Liu H, et al. High-throughput isolation and characterization of untagged membrane protein complexes: outer membrane complexes of Desulfovibrio vulgaris. J Proteome Res. 2012;11:5720-35.

60. Los DA, Murata N. Membrane fluidity and its roles in the perception of environmental signals. Biochim Biophys Acta. 2004; 1666:142-57.

61. Rowlett VW, Mallampalli V, Karlstaedt A, Dowhan W, Taegtmeyer H, Margolin W, et al. Impact of membrane phospholipid alterations in Escherichia coli on cellular function and bacterial stress adaptation. J Bacteriol. 2017;199:e00849-16.

62. Zhou A, Lau R, Baran R, Ma J, von Netzer F, Shi W, et al. Key metabolites and mechanistic changes for salt tolerance in an experimentally evolved sulfate-reducing bacterium, Desulfovibrio vulgaris. mBio. 2017;8:e1780-17.

63. Haveman SA, Greene EA, Stilwell CP, Voordouw JK, Voordouw G. Physiological and gene expression analysis of inhibition of Desulfovibrio vulgaris Hildenborough by nitrite. J Bacteriol. 2004;186:7944-50.

64. Finkel SE. Long-term survival during stationary phase: evolution and the GASP phenotype. Nat Rev Microbiol. 2006;4:113-20.

65. Farrell MJ, Finkel SE. The growth advantage in stationary-phase phenotype conferred by rpoS mutations is dependent on the $\mathrm{pH}$ and nutrient environment. J Bacteriol. 2003;185:7044-52.

66. Clark ME, He Q, He Z, Huang KH, Alm EJ, Wan XF, et al. Temporal transcriptomic analysis as Desulfovibrio vulgaris hildenborough transitions into stationary phase during electron donor depletion. Appl Environ Microbiol. 2006;72:5578-88.

67. Galhardo RS, Hastings PJ, Rosenberg SM. Mutation as a stress response and the regulation of evolvability. Crit Rev Biochem Mol Biol. 2007;42:399-435. 
68. Rolfe MD, Rice CJ, Lucchini S, Pin C, Thompson A, Cameron ADS, et al. Lag phase is a distinct growth phase that prepares bacteria for exponential growth and involves transient metal accumulation. J Bacteriol. 2012;194:686-701.

\section{Affiliations}

Bo Wu $\mathbb{1}^{1,2} \cdot$ Feifei Liu $\mathbb{D}^{2,3} \cdot$ Aifen $\mathrm{Zhou}^{2} \cdot$ Juan $\mathrm{Li}^{4} \cdot$ Longfei Shu $\mathbb{D}^{1} \cdot$ Megan L. Kempher $\mathbb{D}^{2} \cdot$ Xueqin Yang $^{1}$.

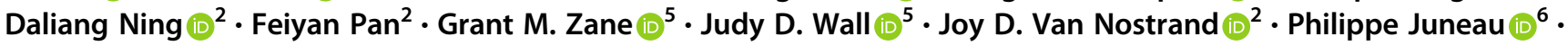
Shouwen Chen $\mathbb{1}^{7,8} \cdot$ Qingyun Yan $\mathbb{1}^{1,2} \cdot$ Jizhong Zhou $\mathbb{( \mathbb { D }}^{2,9,10} \cdot$ Zhili He $\mathbb{1}^{1,2,4}$

1 Environmental Microbiomics Research Center, School of Environmental Science and Engineering, Southern Marine Science and Engineering Guangdong Laboratory (Zhuhai), Sun Yat-sen University, Guangzhou 510006, China

2 Institute for Environmental Genomics and Department of Microbiology and Plant Biology, University of Oklahoma, Norman, OK 73019, USA

3 Guangdong Provincial Key Laboratory of Microbial Culture Collection and Application, State Key Laboratory of Applied Microbiology Southern China, Guangdong Institute of Microbiology, Guangzhou 510070, China

4 College of Agronomy, Hunan Agricultural University, Changsha 410128, China

5 Departments of Biochemistry and Molecular Microbiology \& Immunology, University of Missouri-Columbia, Columbia, MO 65211, USA
6 Départment des Sciences Biologiques, GRIL, EcotoQ, TOXEN, Ecotoxicology of Aquatic Microorganisms Laboratory, Université du Québec à Montréal, Montréal, Canada

7 State Key Laboratory of Agricultural Microbiology, Huazhong Agricultural University, Wuhan 430070, China

8 State Key Laboratory of Biocatalysis and Enzyme Engineering, Environmental Microbial Technology Center of Hubei Province, College of Life Sciences, Hubei University, Wuhan 430062, China

9 Earth Sciences Division, Lawrence Berkeley National Laboratory, Berkeley, CA 94720, USA

10 School of Environment, Tsinghua University, Beijing 100084, China 